EMBRYARIDDLE
Aeronautical University

SCHOLARLY COMMONS

\section{International Journal of Aviation,} Aeronautics, and Aerospace

\title{
FE Modeling Methodology for Load Analysis and Preliminary Sizing of Aircraft Wing Structure
}

\author{
Jun Hwan Jang \\ Defense Acquisition Program Administration, bulbearj@gmail.com \\ Sang Ho Ahn \\ University of Shinhan, South korea, drshahn@naver.com
}

Follow this and additional works at: https://commons.erau.edu/ijaaa

Part of the Aeronautical Vehicles Commons, Engineering Mechanics Commons, Mechanics of Materials Commons, and the Structures and Materials Commons

\section{Scholarly Commons Citation}

Jang, J., \& Ahn, S. (2019). FE Modeling Methodology for Load Analysis and Preliminary Sizing of Aircraft Wing Structure. International Journal of Aviation, Aeronautics, and Aerospace, 6(2). https://doi.org/ 10.15394/ijaaa.2019.1301

This Article is brought to you for free and open access by the Journals at Scholarly Commons. It has been accepted for inclusion in International Journal of Aviation, Aeronautics, and Aerospace by an authorized administrator of Scholarly Commons. For more information, please contact commons@erau.edu. 


\section{FE Modeling Methodology for Load Analysis and Preliminary Sizing of Aircraft Wing Structure}

\section{Cover Page Footnote}

Original research paper and is not being submitted for publication elsewhere. We have reviewed the final version of the manuscript and approve it for publication. To the best of our knowledge and belief, this manuscript has not been published in whole or in part nor is it being considered for publication elsewhere. Thank you very much for your considering our manuscript for potential publication. I'm looking forward to hearing from you soon. Best Regards. Yours Sincerely, Ph.D. Sang Ho Ahn Shinhan University, 95 Hoam-ro, Uijeongbu, Gyeonggi 480-701, Republic of Korea drshahn@naver.com 


\section{Introduction}

The finite element model has a direct impact on time and cost of analysis especially for internal load evaluation and initial sizing of the aircraft which constructed with enormous number of structural elements. Also, as for the development of aircraft, each design phase such as concept design, basic design, and detail design has a separate detailed design objective and has a difference from depth and accuracy of required design and analysis per each phase. Therefore, the finite element model should be developed while maintaining accuracy of overall analysis, adequately simplifying and idealizing in accordance with each design phase, it is a key to the computational structural analysis.

As for the finite element model for internal load analysis of aircraft and initial sizing, it should be built primarily for designers to easily determine the internal load or the level of stress applied to the main joints of aircraft and the main structure. So, for this, it is required to avoid using the beam element or bending plate that has bending stiffness as far as possible, it is suggested to use one-dimensional rod element, two-dimensional membrane, and shear panel that have apparent load path mechanism and simple finite elements. In addition, while not attached to the local characteristics or shape of each structure too much, it is required to correctly reflect the design intent of designer on overall structure particularly the main structure and load transfer concept on joints. In case of constructing the finite element model on the actual aircraft structure, it can take much time for modeling even the fact that it facilitated up-to-date pre-processing and at the basic design phase, those process could be numerously iterated due to the frequent design changes. Therefore, the time takes for modeling should be the one of factors to decide the modeling methodology.

The finite element model developed for internal load analysis and initial sizing of aircraft is activated by adequate analysis solver by applying external load created separately and data. However, since the aircraft is the statically indeterminate structure that has the enormous amount of internal redundancies, the dimension and stress level for each structure are interlinked. Therefore, to design all structures have lower stress level than allowable stress, the iteration calculation applying optimization concept is required.

As for the researches related to aircraft element model, Bruhn (1973) and Niu (1988) arranged theories and practice on analysis and design of flight vehicle. Buehrle et al. (2000) built the finite element model of stiffener, panel, and aircraft fuselage and verified it by experiment modal analysis. Wittenberg et al. simulated post buckling behavior from fuselage structure with aluminum alloy and applied on the fiber metal laminates (FML) material (2001). Bhattacharya et al. (2002) 
developed the shell element that is able to have shear deformation based on theory of Reissner on the smart laminate composite shell analysis, whereas Karaağaçlı et al. (2012) constructed the dynamically equivalent finite element model and presented the method to revise the finite element model of aircraft by using the result of ground vibration test. In addition, van der Ven et al. (2012) developed the modeling framework to decide the structural dynamic load of elements of fuselage and calculated the structural dynamic load of fuselage in relatively easy and cost-efficient way. Yan et al. (2012) presented the calculation method on punch and die boundary condition based on special simulation process and bending line coordinates in order to set the FEM model based on press bending forming process of integrated panel of aircraft. Gennaretti et al. (2013) described transfer process related to internal vibration on vibration load delivered by the wing through detail finite element model of fuselage to evaluate the vibration level of tiltrotor, whereas Kongo Kondé et al. (2013) used the finite element model to model and simulate the interaction between the tire of aircraft and ground considering non-linearity of materials.

Tang et al. (2013) suggested the parametric modeling method of finite element of wing structure of aircraft due to the time-consuming characteristic of preprocess of the finite element analysis. Truong et al. (2013) researched one-dimensional (1-D) and three-dimensional methods to effectively model of rotor blade structure of helicopter and described the accuracy of current structural modeling based on one-dimensional beam theory. The next year, Bergan et al. (2014) conducted modeling of panel of aircraft fuselage and described the longitudinal tension, internal pressure, combined axial tension, damage process applying internal pressure loading condition, and presented the design methodology of damage prevention. Concurrently, Guo et al. (2014) described the development of the finite element (FE) model to research the performance of test tire of aircraft and evaluate the safety criteria, while the dynamic simulation was analyzed to calculate the load of tire in aircraft landing scenario. Kapidžić et al. (2014) developed three-dimensional solid finite element model of composite Al alloy single-lap bolt joint that has titanium joint of counter link. Lim (2014) researched the verification process of satellite finite element (FE) model using analytical sine wave test and dynamic test result. In addition, Sasaki et al. (2014) conducted the self-weight deformation test and stretch forming test that have large radius of curvature in order to research the maximum simulation parameters that enable to accurately expect spring back and self-weight deformation on fuselage skin. Kumar and Mishra (2016) idealized main components of aircraft including dynamic mass, stiffness matric, base plate, installed frame, arm, support frame, 
propeller and whirl set and modeled quad copter. Most recently, Herrada et al. (2017) presented new and innovative methodology to accelerate parametric analysis on large structure under dynamic load.

In this paper, as a means of systematization and standardization of computational structural analysis of aircraft methodology, the load path of wing structure of subsonic military aircraft reviewed and presented the finite element modeling methodology for calculation of internal load and initial sizing on main structure and joints. The subject structure of research was the multi-spar type of aircraft wing that mostly adopted on up-to-date military aircraft being developed and modelled under the environment of widely used structural analysis program, MSC/NASTRAN. In addition, by applying multi-load case on the developed finite element model, the initial sizing procedure that can decide the initial sizing was presented for all structures to have lower level of stress than allowable stress level.

\section{Finite Modeling for Aircraft Wing Assembly}

\section{Objective of Aircraft FE Modeling}

The full-scaled finite element model was built with entire aircraft as an one finite element model by combining each modeled structure that constructing the airframe. Most of cases, the accuracy of full-scaled model has a direct impact on the analysis result since the detailed stress analysis of each component is conducted by using internal load calculated from the full-scaled model.

The full-scaled model is a classic coarse grid FEM and facilitated as below purposes:

- Load path verification of structures

- Calculation of internal load and free body load

- Calculation of stiffness and displacement of structures

The full-scaled finite element model includes all main structure members that construct the aircraft in order to accurately calculate the internal load. In addition, when modeling each member, it was more focused on accurately reflecting stiffness of structure that has impact on internal load distribution than reflecting the actual structure configuration in detail. The detail finite element model most applied for unit item analysis is facilitated as below purposes.

- When difficult to achieve accurate internal load by calculation or 
coarse grid FEM

- When calculating stress distribution and stress level for durability or damage tolerance analysis on the area that created concentrated stress

- In case of the fitting with complex load path or cutout

- During structural test, in order to accurately expect the strain on the strain gage position where damage possibly occurred.

During development process of aircraft, the full-scaled finite element model has been facilitated from the basic design phase for main structure assignment. In the initial design phase when the main structure assignment and sizing have not been decided, most of web was modelled as shear element, skin was modelled as membrane element and longitudinal member was modelled as rod element. Then, entering the detail design phase, as the maturity of design was increasing, most of structures were modelled as shell element that has bending stiffness to calculate actual internal load and it resulted in some weight loss. Also, as the use of shell element increased, it became possible to directly apply the constructed the full-scaled model on dynamic analysis in order to calculate internal load without modification work. Figure 1 shows the changes in maturity of full-scaled model per design phase based on the number of elements and nodal points used in model. 


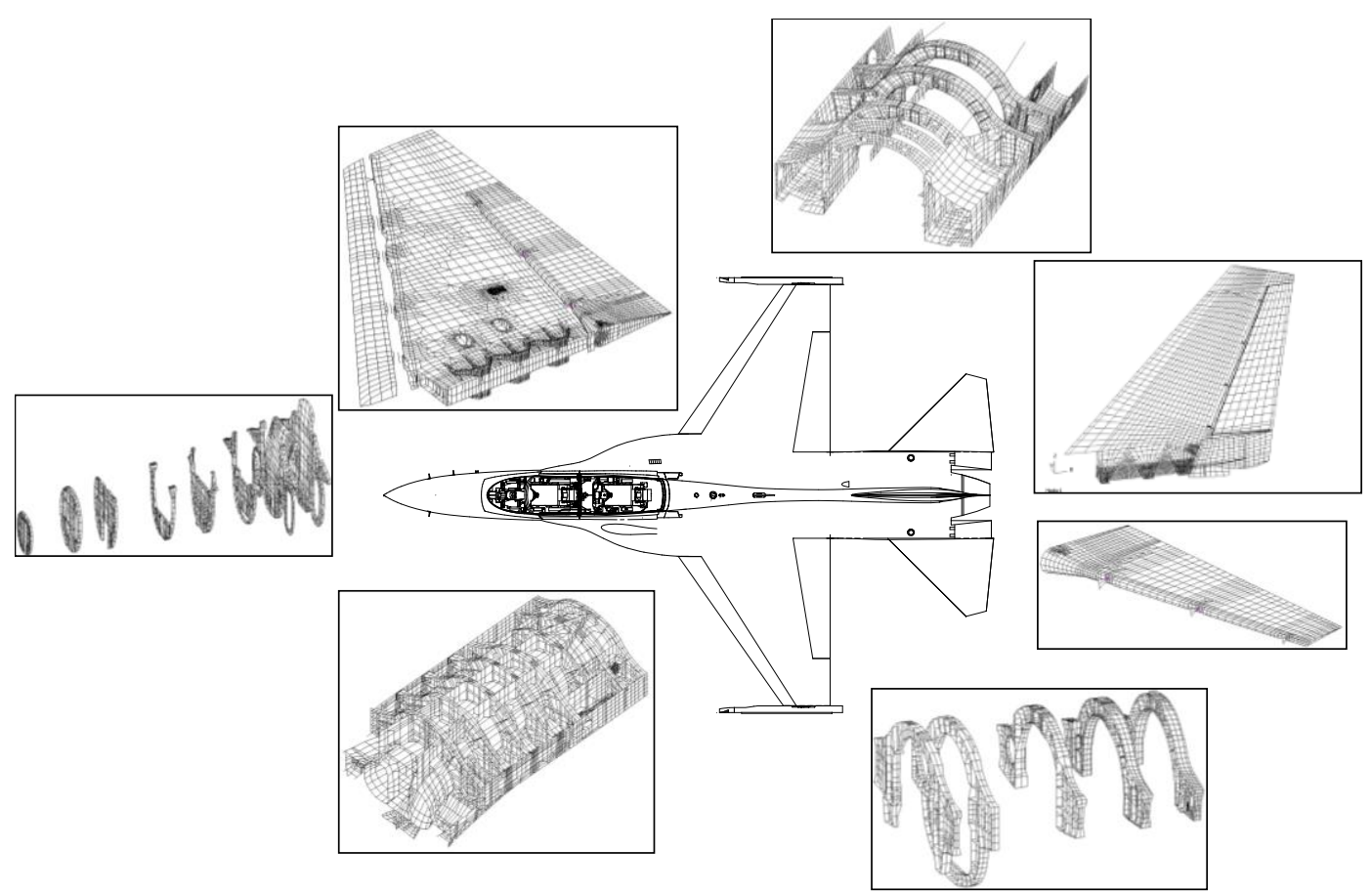

Figure 1. Finite element model for load analysis \& preliminary design of aircraft.

During development process of aircraft, the full-scaled finite element model has been facilitated from the basic design phase for main structure assignment. In the initial design phase when the main structure assignment and sizing have not been decided, most of web was modelled as shear element, skin was modelled as membrane element and longitudinal member was modelled as rod element. Then, entering the detail design phase, as the maturity of design was increasing, most of structures were modelled as shell element that has bending stiffness to calculate actual internal load and it resulted in some weight loss. Also, as the use of shell element increased, it became possible to directly apply the constructed the full-scaled model on dynamic analysis in order to calculate internal load without modification work.

\section{Aircraft wing-box.}

The wing box consists of skin, spar and rib. Generally, the skin of the wing of supersonic and multi-spar aircraft is the most important component to support not only for torsion of wing but for the bending load. However, the 
self-bending stiffness was not considered at the basic design phase and having the upper and lower skins support the flap wise tension and compression load, the bending moment extended on the wing can be supported as a result. Therefore, as shown in Figure 2, it is adequate that the skin of the wing should use the membrane element that can transfer only the in-plane tension, compression and shear load. This can have more conservative result than considering bending stiffness and effective method that can allow to easily calculate the internal load and reduce the calculation time at the detail design phase.

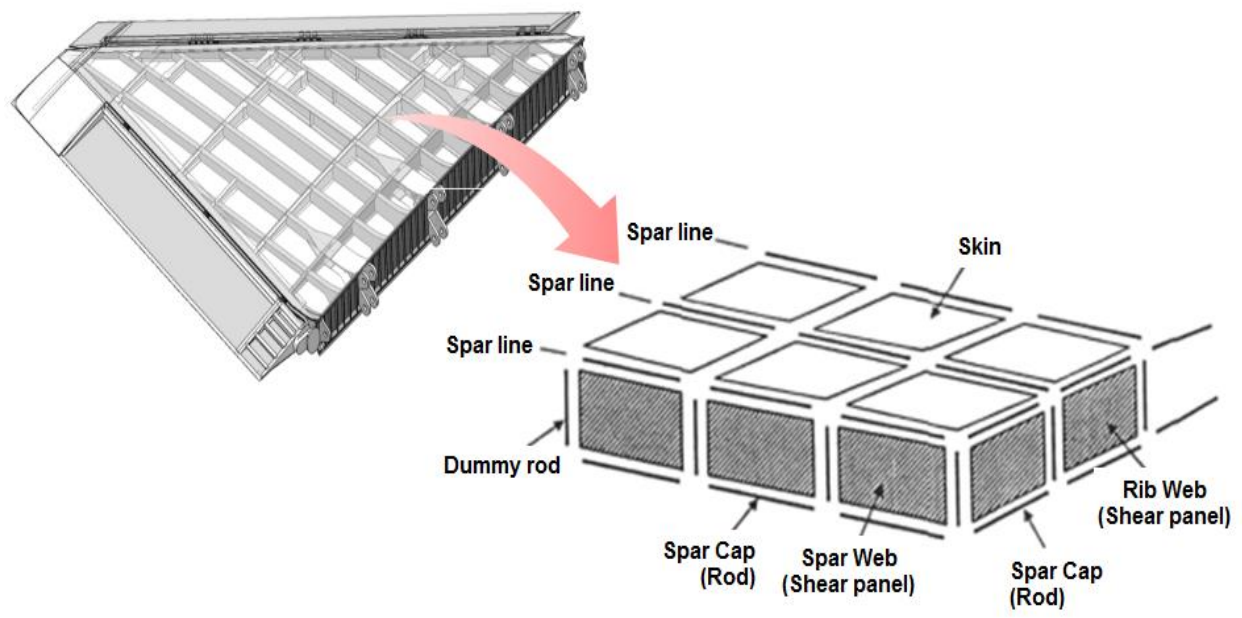

Figure 2. Idealization of aircraft wing box structure.

The structural function of spar in multi-spar wing is to support the shear force applied on the wing and improve the buckling capacity of skin. The flange of spar is aimed to install spar on the skin and it can support the part of bending moment applied on the wing as a compressed form. Therefore, the web of spar was modelled as a shear panel that only support the pure shear load and the flange was modelled as a rod element that only support one-dimensional load. Along with spar, the rib, the other internal structure, is mainly used for hard point to install outside attachments or for transferring the concentrated load delivered by leading flap or flaperon. Therefore, the rip that used for hard point, it should be modelled as three-dimensional solid element in a strict sense but, there is a main purpose for rid modelling to find out the size of load and its path delivered at the basic design phase. Same as spar, it is common that the web of rib is idealized as 
shear panel, the flange is idealized as rod element.

\section{Flaperon.}

The sandwich structure shown in Figure 3 has great characteristics like lightweight, bending stiffness so it is widely used in control surfaces like flap, aileron and rudder both in military aircraft and commercial aircraft. Therefore, in this paper, the finite element modeling methodology on the flaperon activated by hydraulic system was presented as a form of honeycomb core sandwich structure. There are various methods to idealize honeycomb core sandwich structure, two of methods are mostly used among them.

First, as presented in Figure 3, the membrane that is in charge of face material and in-plane load of sandwich structure, the core is idealized as shear panel that have on the transverse shear stiffness. Also, the rod element is installed transversely to remove transverse numerical instability and complement the minute longitudinal stiffness on the core. In the second method, the face material same as in first is modeled as membrane but, the core is modeled as three-dimensional solid element and shown as in Figure 3. In this paper, the second method selected that enables the calculation of all forms of transverse three-dimensional stress to conduct the research on de-bonding of face material and core afterward. In addition, it can be another reason for design engineers to favor the model that use the solid element in terms of time consuming to finite element modeling, the second method is advantageous. 


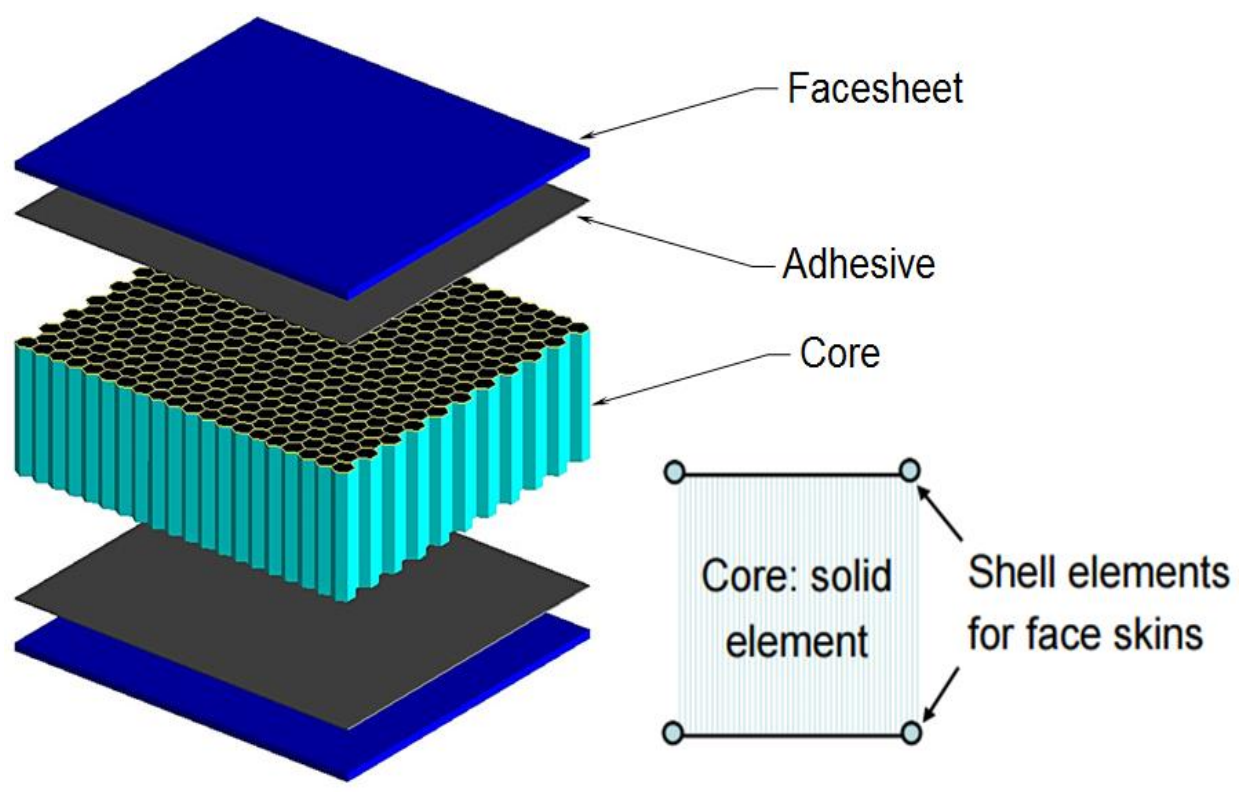

Figure 3. Idealization of honeycomb core sandwich structure.

Along with idealization of sandwich structure, the important part in finite element modeling of flaperon is the idealization of joints of flaperon. The most of subsonic military aircraft developed recently has an activation method that flaperon is installed on the trailing spar of the wing by several hinges and activate by hydraulic cylinder that installed in inside of fuselage. Therefore, the bottom line of flaperon idealization at the basic design phase is to model in order to accurately calculate the load on each hinge and the reaction force on internal part of fuselage.

In this paper, it was designed that each hinge can transfer the load only excluding the moment and at the same time the movement of hinge axis direction can be created freely. Also, as for the alignment of flaperon, the movement of longitudinal direction of hinge axis can be set freely in the internal and outside of hinges excluding the center hinge. The hinges and hydraulic cylinder are modeled as rod element and therefore, the hinge moment in flaperon can be calculated as multiply of the load on rod element of hydraulic cylinder and the longitudinal distance from hinge axis. Also, the reaction force from each hinge and supporting points can be easily decided from the node force from the related node. 


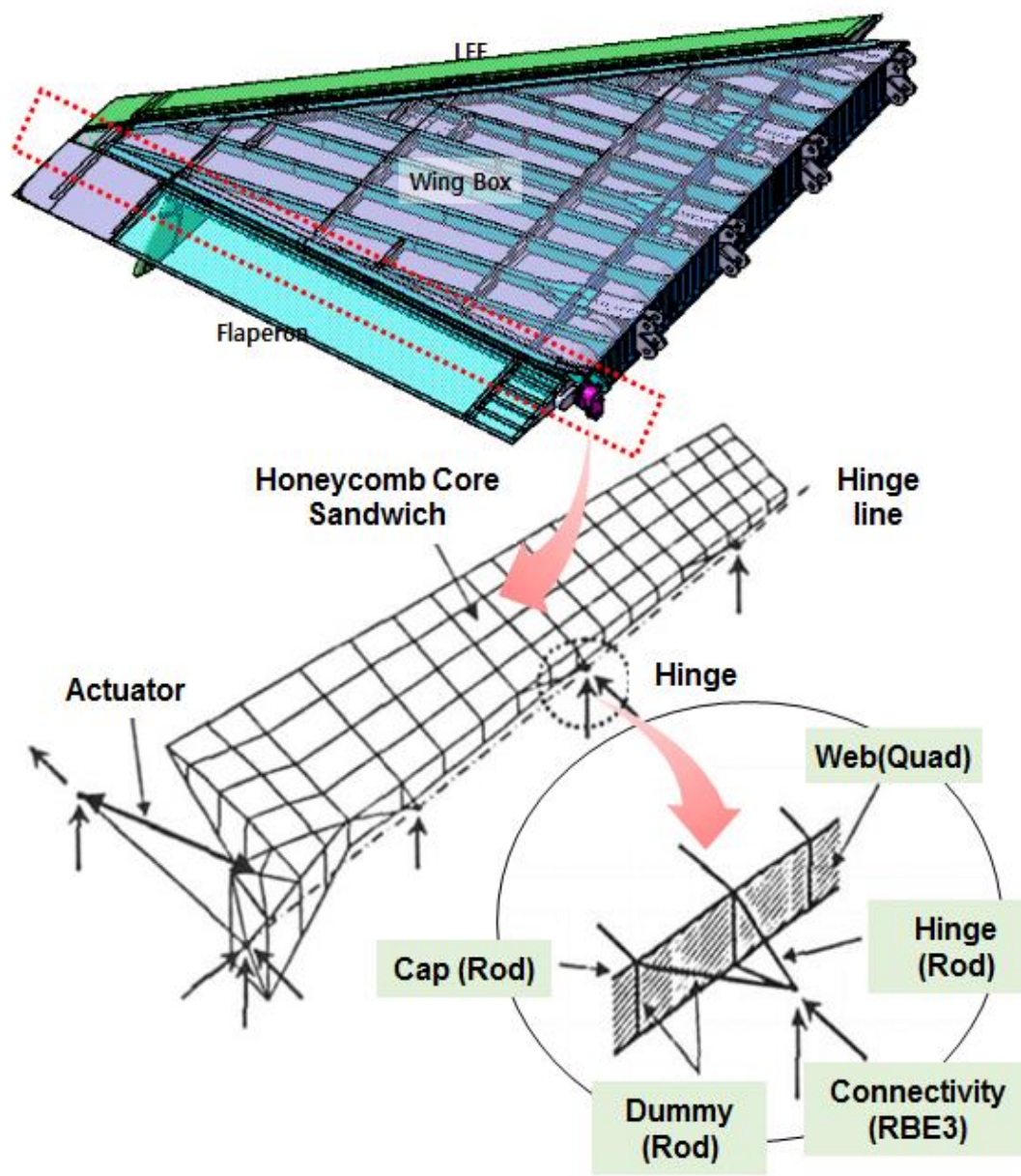

Figure 4. Finite element model example for flaperon.

In Figure 4, the thick arrow shows the degree of freedom of bind in supporting point and joints. The hinge load and moment achieved from the internal load analysis using this model, it should be same as the hinge load and moment by outside load created load group and whether it is same as the load and moment by two methods can be the standard for feasibility review of finite element model.

\section{Leading edge flap.}

As for the leading-edge flap, it is mostly installed in the entire part of 
leading-edge flap of aircraft and therefore, it has a characteristic of slenderness ratio. With this geometric characteristic, the leading-edge flap is weak for bending, as such, it is difficult to directly transfer the torque to the entire structure with one hinge axis within fuselage as the way of the flaperon. Therefore, most of aircraft takes a method to use several rotary actuators and directly transfer the torque in each hinge that is required for leading edge flap.

As such, not like flaperon, the hinge of leading-edge flap has to transfer not only the shear and vertical force but, the torque. However, when idealizing the hinge of the leading-edge flap with using one-dimensional element same as the hinge of flaperon, the one-dimensional element come to receive the bending moment by the driving torque. So, in this case, instead of using rod element, the general beam element has to be used for modeling and other parts will be same as the flaperon modeling methodology.

\section{Wing Attachment Fitting}

If it is not all-in-one, the way to install the aircraft wing to fuselage is divided into the lug method and the tension bolt method. In this paper, the modeling methodology for tension bolt is presented that is adopted for F-16 aircraft. The tension bolt method is the way that all shear, bending and torsion load on the wings are transferred to wing-carry-thru-bulk-head of fuselage by wing-to-Fuselage attach. Fitting and tension bolts installed on the root of the wing. When applying this concept, it is very important to accurately calculate the load on each fitting and tension bolt.

As shown in Figure 5, as for the fitting, it is the bending plate element having bending stiffness. As for the tension bolt, it used three spring elements that can simulate three loads, vertical and horizontal shear forces and tension force. In addition, since the pre-post shear tie only supports the shear force excluding tension force, the idealization was conducted using two spring elements. 

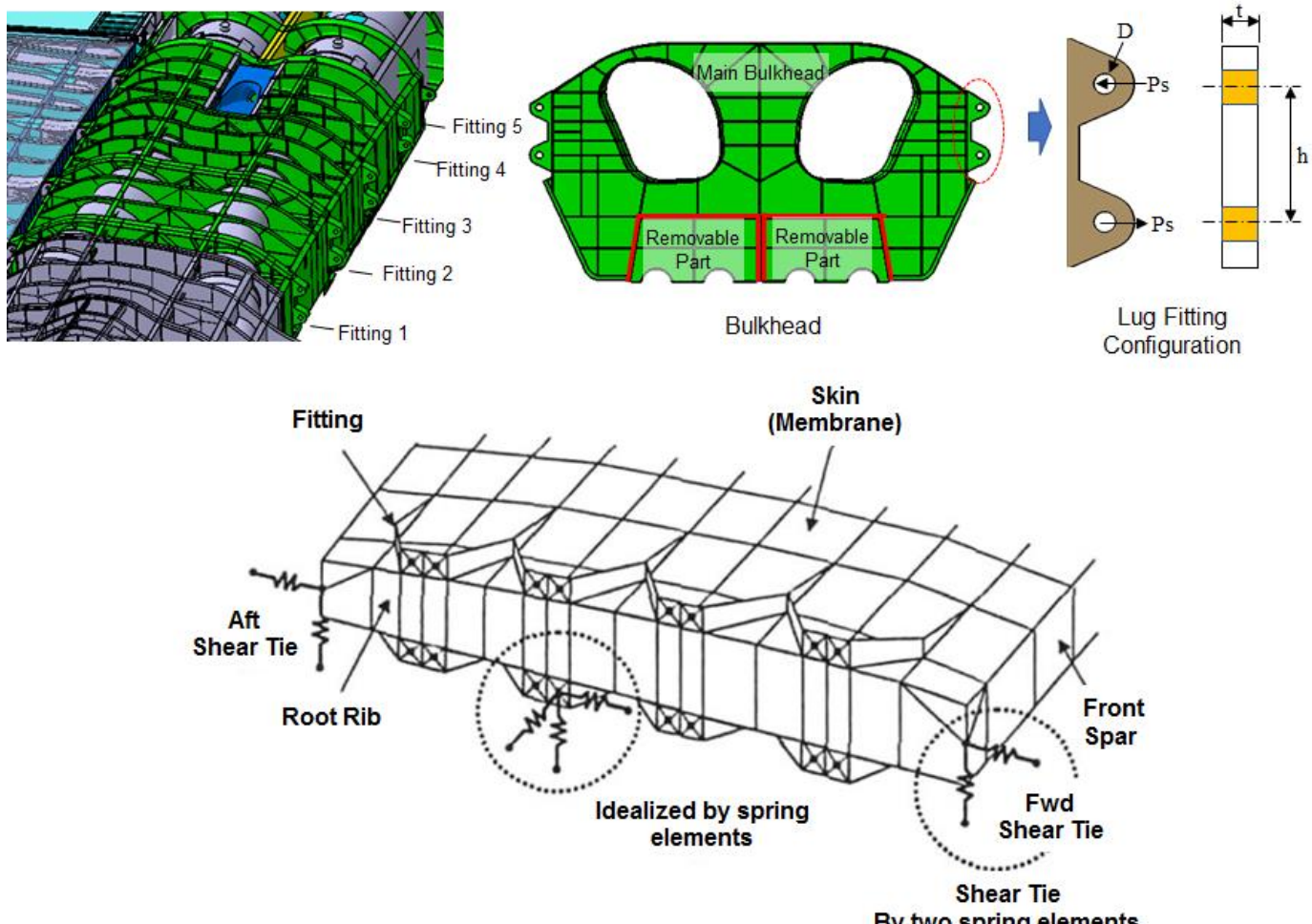

Figure 5. Finite element model example for wing attachment fitting.

Therefore, it was possible to calculate for the tension force on the tension bolt, drag and vertical shear force in two directions and two shear forces on the shear tie. In this case, the tension bolt came to the combined load state on which the tension and shear forces simultaneously applied. In this kind of combined state, the bolt strength will be decided as below formula (Bruhn, 1973).

$$
R_{S}{ }^{3}+R_{t}^{2}=1
$$

In here, $R_{s}$ and $R_{t}$ represent the current stress ration on each shear allowable stress and tension allowable stress. In addition, the bending moment on root of wings can be calculated from tension force and compression force applied on top-and-bottom tension bolts. As same as the flaperon, the sum of load and moment calculated from the internal load on each tension bolt should be same as the sum of load and moment by external load. As mentioned on the introduction, the wings of aircraft are the statically indeterminate structures, the distribution of 
load and moment on the root of wings can be varied by the stiffness of tension bolt, the stiffness of spring. Therefore, when iterating calculation for initial sizing, separate analysis on tension bolt should be conducted in accordance with formula (1) and the spring constant for idealization of tension bolt is decided as below (Swift, 1990).

$$
\begin{aligned}
& K_{T}=\frac{E A}{L}, K_{s}=\left[\frac{B}{E^{l} D}+C\left(\frac{1}{E_{f} t_{f}}+\frac{1}{E_{b} t_{b}}\right)\right]^{-1}, \\
& E^{l}=\frac{1}{2}\left(\frac{1}{E_{f}}+\frac{1}{E_{b}}\right)^{-1}
\end{aligned}
$$

In here, $\mathrm{K}_{\mathrm{T}}$ and $\mathrm{K}_{\mathrm{S}}$ are the spring constants for each tension force and shear force and E, A, L means elastic modulus, cross-section area and length respectively. $E_{f}$ and $E_{b}$ are the elastic modulus of fitting and bulk head end pad respectively and tf and tb are the width of fitting and bulk head end pad respectively. $\mathrm{D}$ is the diameter of bolt and $\mathrm{B}$ and $\mathrm{C}$ are the constant decided by materials.

\section{Number System}

The finite element model of wings used in this paper consists of approximately 5,000 EA of elements and 2500 EA of nodal points. In general, the number of elements and node used for finite element model for aircraft is varied by the sophistication of model, as for the finite element model for initial sizing and internal load analysis of military combat aircraft at the basic design phase, it was known that the number of elements and node accounted for tens of thousands respectively. Therefore, each aircraft manufacturers in advanced countries are building adequate numbering system of elements and nodes so that it can be able to find out on which the module or which component are the element and node installed with only the number of element and node. In the same manner, the numbering system was set as below for finite element model for wings.

The numbers for finite elements consist of 7 numbers in total, "ABCDEFG" and the first number A represent the unique number of modules, $\mathrm{B}$ is the form of element, $\mathrm{C}$ is the number of component and EFG represents the serial number of elements. As for the form of element, depending on the result of B, it represents 1(Rod), 2(BAR), 3(Membrane), 4 (Bending Plate), 5(Shear Panel), 
6(Solid), 7(Spring). In addition, depending on result of $\mathrm{C}$, it represents 1(Wing Box), 2(Leading Edge Flap), 3(Fixed Trailing Edge), 4(Flaperon), 5(Wing-to-Fuselage Attach. Fitting). And if D is 1, it means upper side of wing and if it is 2 , it means the bottom face. The numbers for nodes, it consists of six numbers in total," ABCDEFG". The first number A means the unique number of modules, $\mathrm{B}$ is the number of components, $\mathrm{C}$ is the location and DEF means the serial number of nodes.

\section{Wing Assembly FE Modeling Methodology of Aircraft}

\section{Shear Web with Cutout}

The shear web is the member that is mainly supporting shear force. In full-scaled fuselage model, if there is a cutout or hole in shear web, the modeling methodology is used to directly reflect the configuration on the model or use the equivalent thickness reflecting the lowered shear stiffness of web due to the hole. If it uses the equivalent thickness, the equivalent thickness of the web with no hole that has the same shear stiffness is calculated and then, the result will be set as the thickness of element and modeled with the form of no hole. Figure 6 shows the curve that calculates the equivalent thickness on the web with a hole.
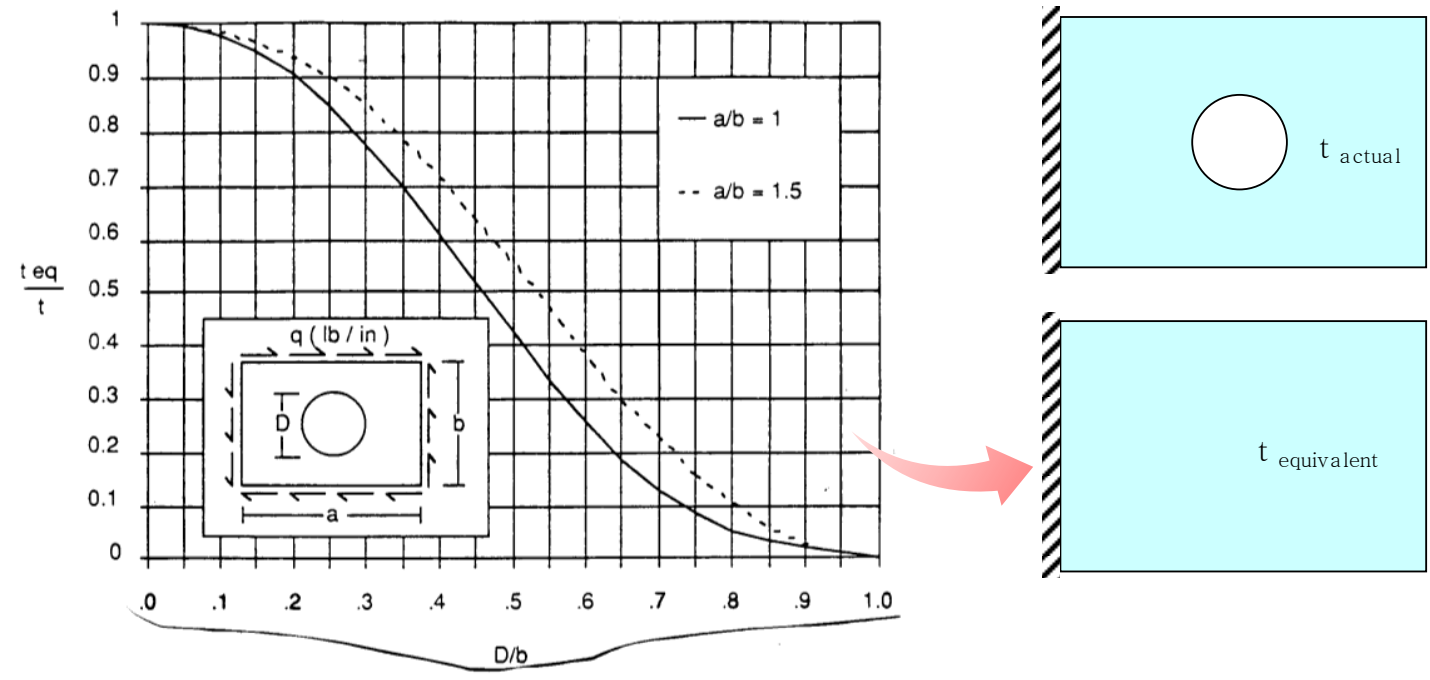

Figure 6. Equivalent thickness curve for web with hole. Adapted from "Airframe Structural Design, by M C. Y. Niu, 1998, Technical Book Company, CA.

\section{Skin}

All skins are modeled as the cell elements with bending stiffness. Since 
element nodes of skin are located on OML, in order to revise in, the offset has to be applied on shell element. As for the removable panels, its material stiffness is adequately reduced based on the direction of application of the load reflecting the flexibility of joints. The spar web with the shear load as the main design load, its laminate angle of [0/45/90] consists of (30\% 60\% 10\%) with ratio of [30\%/40\%/30\%]. The axial load of skin and flange is the main design load and its laminate angle of $[0 / 45 / 90]$ consists of ratio with $(50 \%, 40 \%, 10 \%)$.

\section{Longitudinal Structure}

The web of all components of longitudinal member is modelled as a shell element with bending stiffness. The flange and stiffener are modeled as rod or shell element. The Longeron is also modeled as rod element and at this time, the area of rod element is calculated as in Figure 7.

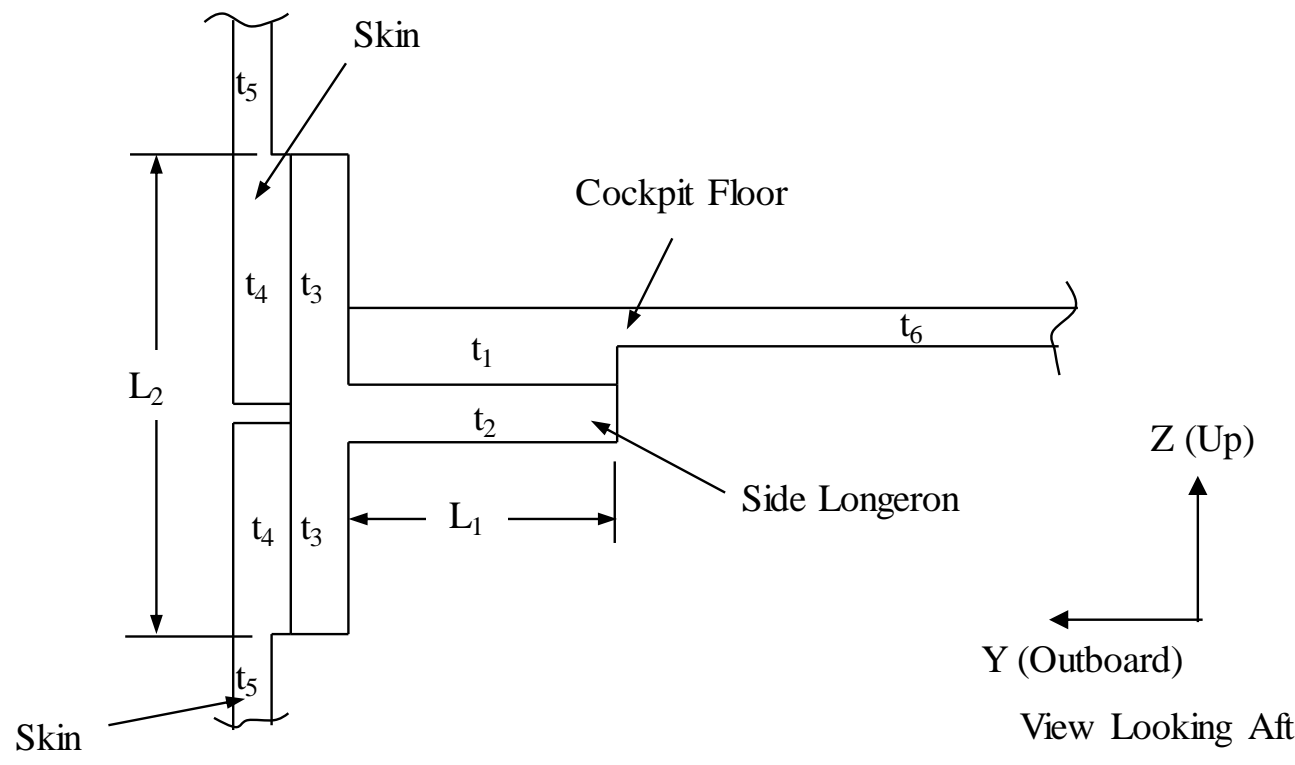

$$
\begin{aligned}
& \mathrm{A}_{\text {rod }}=\mathrm{A}_{\text {stiffener }}+\mathrm{A}_{\text {skin }} \\
& \mathrm{A}_{\text {rod }}=\left(\mathrm{L}_{1}\right)\left(\mathrm{t}_{2}\right)+\left(\mathrm{L}_{1}\right)\left(\mathrm{t}_{1}-\mathrm{t}_{6}\right)+\left(\mathrm{L}_{2}\right)\left(\mathrm{t}_{3}\right)+\left(\mathrm{L}_{2}\right)\left(\mathrm{t}_{4}-\mathrm{t}_{5}\right)
\end{aligned}
$$

Figure 7. Example of calculating area of a longeron rod element.

The spar web is modeled as shell element and spar flange and stiffener are modeled as rod element with equivalent area. 


\section{Composite \& honeycomb structure.}

The skin of main wing and tail wing consist of composite material. The skin of composite material is modelled using shell element as in Figure 8 and the order and direction of composite material laminates are defined suing PCOMP card. The material property of composite material is defined using MAT 8 card. All control surfaces excluding horizontal tail wing consist of aluminum honeycomb core structure. The top and bottom surface material of honeycomb core structure is modeled as shell element. The honeycomb core is the core material and is modeled as solid element, the material property of core is defined as anisotropic material following direction of ribbon.

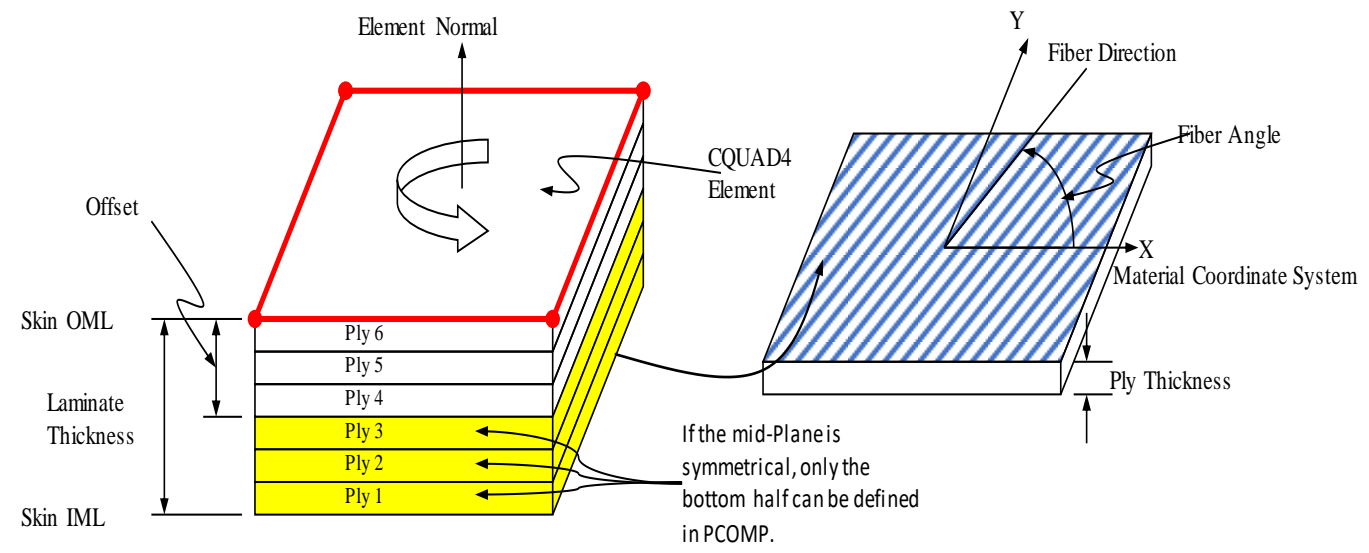

Figure 8. Composite modeling of wing skin.

\section{Structural Analysis of Full-scaled Aircraft}

\section{Sizing Procedure}

The internal force and initial sizing decided in this paper, the stress of all structures under all load conditions should not be beyond the allowable stress level. The analysis procedure presented in Figure 9 is summarized as below. First of all, the load conditions expected to create high stress on aircraft structures are applied to the finite element model, conduct the structural analysis and then, the stress on all finite elements is calculated. After that, the highest stress value is found among the stress created by stress conditions to each finite element and calculate the margin of safety comparing with allowable stress for related 
element.

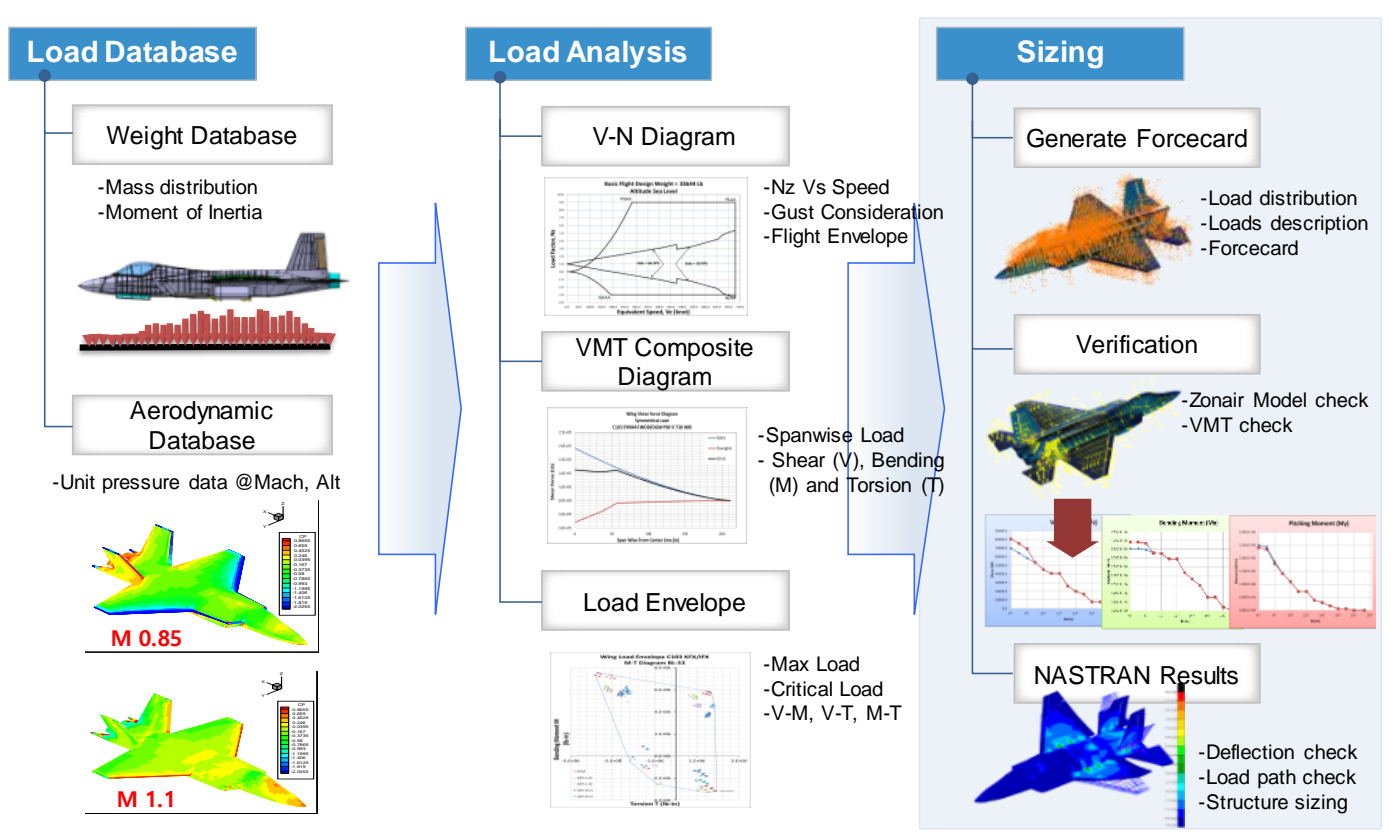

Figure 9. Load analysis \& preliminary design procedure.

At this time, the two-dimensional element such as CQUAD4, CTRIA3 sets the Von Mises stress, the two-dimensional shear panel element such as CSHEAR sets the maximum shear stress and the one-dimensional element such as CROD sets the axial stress as a comparison basis. When the stress on each finite element is above the allowable stress, in other words, the value of the margin of safety is minus, the sizing, thickness or area of element should be increased based on the margin of safety and when it is the opposite, the dimension should be reduced as much as the difference to enhance the stress.

In this paper, the margin of safety used for initial sizing of all structures excluding tension bolt is defined as in formula (3).

Margin of Safety $M . S=\frac{F}{f}-1$

In formula (3), $\mathrm{F}$ represents the allowable stress of material and $\mathrm{f}$ represents the current stress. The sizing data modified is automatically stored as input card for structural analysis solver and using data inputted, the structural analysis is iterated for all load conditions. By this process of iterations, the stress 
level can be maintained below the level of allowable stress to all finite elements.

It was confirmed that most of elements came to have the stress level below the level of allowable stress within margin of error. The dummy element used for removing numerical instability during initial sizing and some elements with bending stiffness are excluded for initial sizing. In addition, the adequate level of minimum gage for all elements was to be set so that it could not be below the level of minimum sizing in terms of productivity even if the stress level is very low. After conducted all the processes above, when the initial sizing for all structures are done, the stress value applied on each structure comes to the internal force for the structure.

Finally, the load condition that created the maximum level of stress on each finite element comes to the critical load condition and at the basin design phase, the critical load condition is set in few multiple numbers to prepare future design modification. At the same time, as for the detailed analysis required, the detail finite element analysis or analytical calculation is conducted. In general, these processes are conducted at the detail design phase but, if it is required at the basic design phase it can be proceeded. For example, the size of tension bolt has a great impact on the internal load distribution of wings, the separate analysis will be conducted when calculation is iterated so that the stiffness of spring element can be modified based on modified sizing.

\section{Wing Finite Element Model}

The coarse grid FEM was built to review the adequacy of load transfer path based on structural arrangement and create the internal load required for stiffness analysis. The coarse grid FEM has the different concept from the finite grid FEM, it is focused on adequately simulating the stiffness allocation of overall main structures and simplifying the configuration to confirm internal load distribution between structures. The FEM solver used for analysis was MSC/NASTRAN and the MSC/PATRAN was used as pre/post processor. Most of structures was created the two-dimensional element (CTRIA3, CQUAD4), the spar/rib flange or stiffener which the main load is the axial load was used the one-dimensional element (CROD). In addition, the control surface was assumed as honey comb material was used the three-dimensional element (CHEXA, CPENTA) to simulate the three-dimensional configuration. 
To simulate values of material property of composite material lay-up, the PCOMP card was applied on the two-dimensional element, the MAT8 card was used to represent the values of material property of lamina having the -two-dimensional orthotropic property. As shown as in Figure 10, the wing configuration of wings were simulated as the finite element model. The modeling was constructed with the elements such as CBAR, CROD, CQUAD4, CTRIA3 elements. The skin of wings consists of different pattern of laminates per each sections of wings based on impact of load and combined.

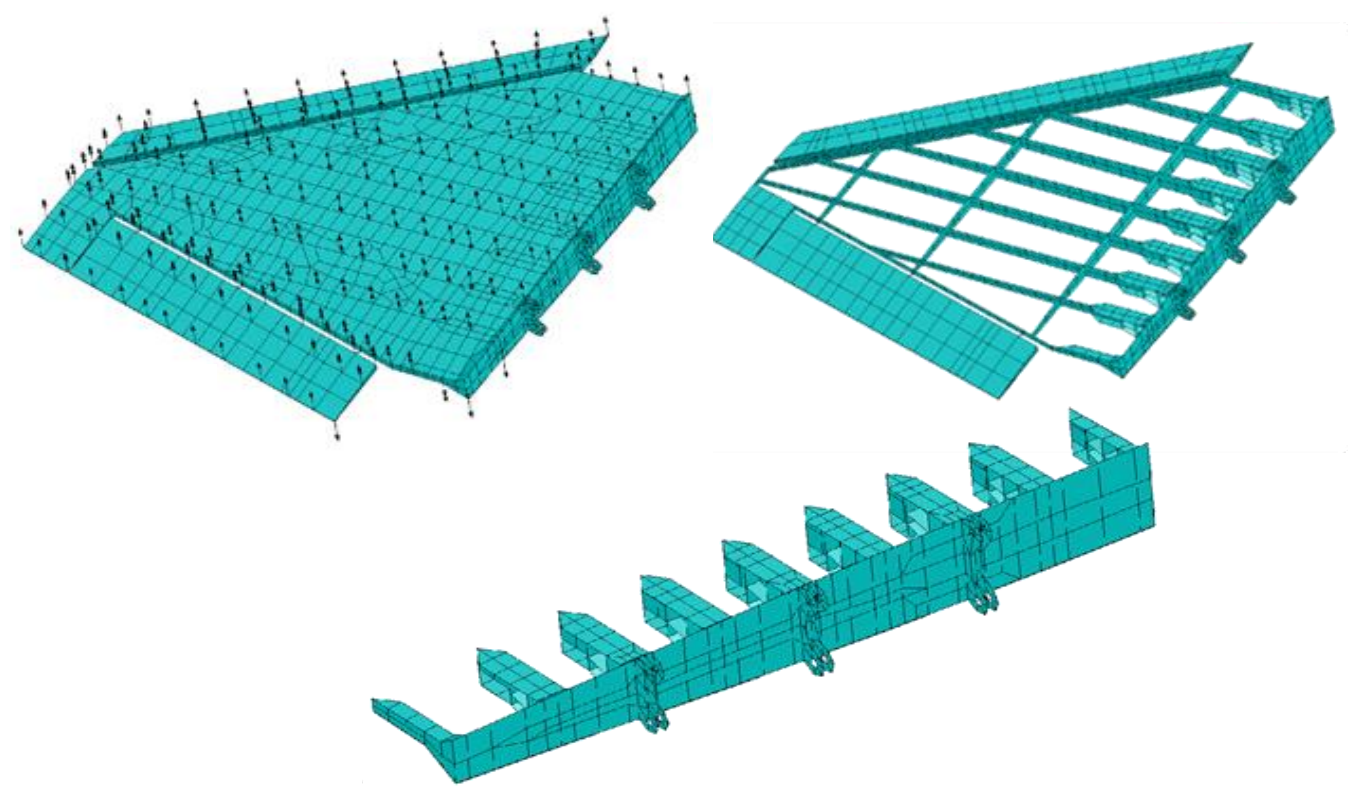

Figure 10. Finite element model of main wing and under structure.

The actual main wings of aircraft have different stiffness per joint position when connected with fuselage, the load distribution per joint is affected by stiffness around the fuselage but, in this phase, it is not allowed to distribute the stiffness around the fuselage as same as the actual. In this analysis, the spring elements were used on the wing attach lug position and the boundary condition was applied on the one edge of the spring elements. The external loads such as aerodynamic pressure, drag and inertial load have the form of distribution load, the nodes that will be applied by the load were separately selected in order to adequately distribute those onto the model. The selected load nodes were the nodes of skin having under structure, it was intended to prevent from having main influence factor of the load applied the nodes to the analysis result on adjacent 
area.

\section{Load analysis of FE model.}

The two critical conditions $(+9 \mathrm{~g} \&-3 \mathrm{~g})$ based on the maximum bending load of the main wings were selected and used as the design load. The shear force, bending moment and pitching moment per BL station were calculated based on the expected load of wings and then, using linear algebra, the load was created by the method that the distribution load that meets above results was distributed to the main wings.

The internal load was calculated from the finite element model and external load described aforementioned paragraph. Figure 11 shows the configuration of deflection on the $+9 \mathrm{~g}$ load condition. Approximately 12 inch of the maximum displacement can be confirmed under the ultimate load (1.5 x limit load) that usually facilitating for calculation static strength.
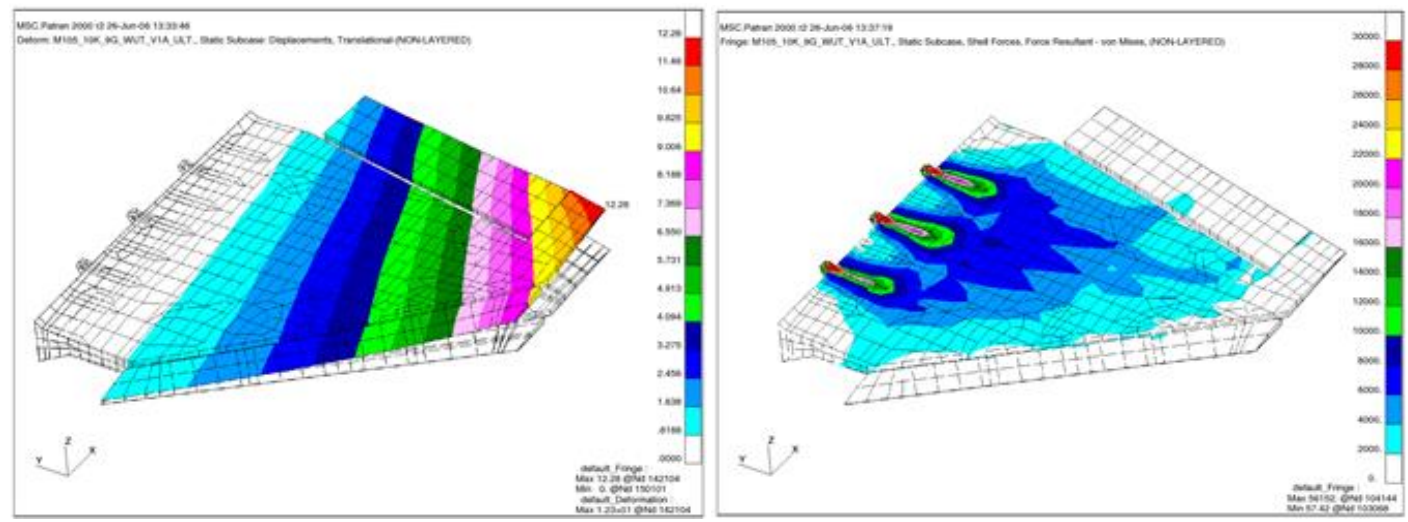

Figure 11. Maximum deflection \& load distribution of main wing.

Figure 11 shows the skin shell force distribution. As approaching to the inboard direction, the size of load transferred is increased and it can be confirmed that the maximum load was transferred from three positions of wing-fuselage joint.

Table 1 shows the result of calculation of the wing attach load per position of joint that is the interface load of main wing and fuselage. The ratio of force transferred to the fuselage by joint located in the center is $27 \%$ which is the highest and as proceeding to the front and back, it can be confirmed that the load sharing was decreased. 
Table 1

Wing Attach Load Distributions (+9g, Ultimate)

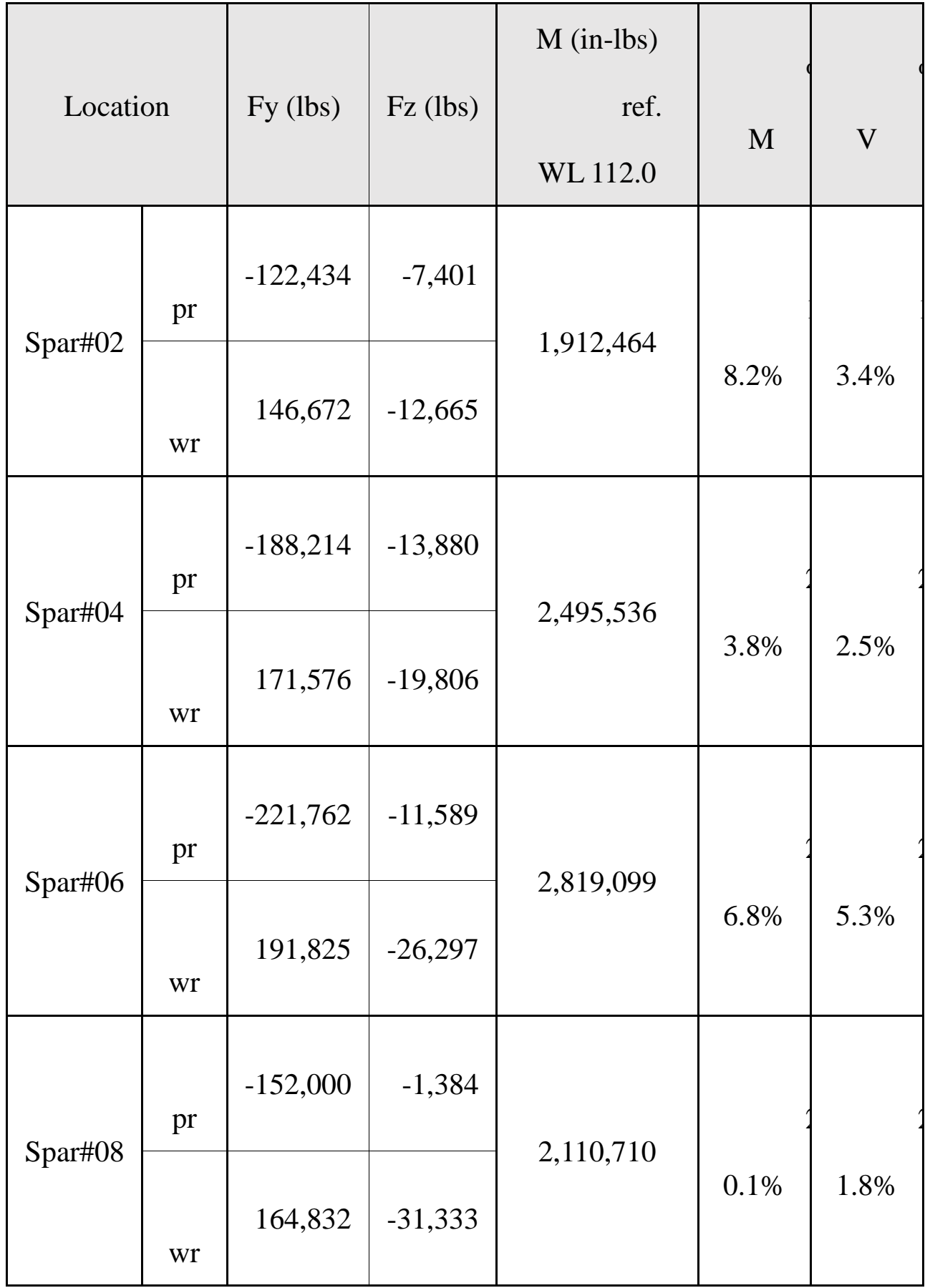




\begin{tabular}{|c|c|r|r|r|r|l|}
\hline \multirow{2}{*}{ Spar } & pr & $-80,513$ & 2,423 & & & \\
\cline { 2 - 7 }$\# 10$ & & 90,017 & $-28,068$ & & & \\
& wr & & & & $1,162,248$ & \\
\end{tabular}

\section{Strength analysis results of FE model.}

The analysis conducted from two different perspectives in order to evaluate the strength of each structure. First, 0.25 " diameter of open hole strength on the in-plane load of each laminate panel was evaluated. And then, the ply strength was evaluated though stress analysis per each ply consisting composite laminate panel. The ply strength evaluation was conducted on both max. strain criteria. The value of margin of safety on the open hole strength is calculated as below.

$$
M . S=\min \left(\begin{array}{l}
\frac{\text { Stress }_{\text {tension allowable, open hole }}}{\text { Stress }_{\text {tension average }}}-1, \frac{\text { Stress }_{\text {compression allowable,openhole }}}{\text { Stress }_{\text {compression average }}}-1, \\
\frac{\text { Stress }_{\text {shear allowable,openhole }}}{\text { Stress }_{\text {shear average }}}-1
\end{array}\right)
$$

The values of open hole allowable stress are used as in Table 2 . 
Table 2

Open Hole Allowable Stress $\left(265^{\circ} \mathrm{F}, 1.2 \% \mathrm{Wet}\right)$

\begin{tabular}{|c|c|c|c|}
\hline \% Lay-up & Tension (psi) & $\begin{array}{c}\text { Comp. } \\
\text { (psi) }\end{array}$ & Shear (psi) \\
\hline$[30 \% 60 \% 10 \%]$ & 30800 & 19600 & 15700 \\
\hline$[50 \% 40 \% 10 \%]$ & 46800 & 25000 & 13700 \\
\hline
\end{tabular}

The strength ratio is defined as below and each value can be derived from failure index formula and as for the NASTRAN, the analysis solver, the strength ratio value calculated from inside can be printed.

Strength Ratio $(S R)=\frac{\text { Allowable stress }}{\text { Calculated stress }}$

The value of ply strength margin of safety by max. strain criteria is calculated as below.

$$
\begin{aligned}
& F . I(\text { Failure Index })=\max \left(\frac{\varepsilon_{11}}{\varepsilon_{11, \text { allowalbe }}}, \frac{\varepsilon_{22}}{\varepsilon_{22, \text { allowalbe }}}, \frac{\gamma_{12}}{\gamma_{12, \text { allowalbe }}}\right) \\
& M . S=\frac{1}{F . I}-1 \text { or } S R-1
\end{aligned}
$$

The values of ply strength allowable used for analysis are as in table 3 . 
Table 3

T-300/5208 Tape at $227^{\circ} \mathrm{F}$ Wet (1.2\%)

\begin{tabular}{|c|c|c|c|c|c|}
\hline \multicolumn{2}{|c|}{ Properties } & \multicolumn{2}{|c|}{ Ult. Strain (B-Allow.) } & \multicolumn{2}{|c|}{ Ult. Stress (B-Allow.) } \\
\hline $\mathrm{E}_{11}(\mathrm{psi})$ & 19152158 & $\varepsilon_{1 \mathrm{~T}, \mathrm{alw}}(\mathrm{in} / \mathrm{in})$ & 0.00775 & $\mathrm{X}_{\mathrm{T}}(\mathrm{psi})$ & 148297 \\
\hline & & & 0.00087 & & 1009 \\
\hline $\mathrm{E}_{22}(\mathrm{psi})$ & 1159639 & $\varepsilon_{2 \mathrm{~T}, \mathrm{alw}}(\mathrm{in} / \mathrm{in})$ & $(0.005447)$ & $\mathrm{Y}_{\mathrm{T}}(\mathrm{psi})$ & (6317) \\
\hline $\mathrm{G}_{12}(\mathrm{psi})$ & 542772 & $\gamma_{12, \text { alw }}(\mathrm{in} / \mathrm{in})$ & 0.01163 & S (psi) & 3555 \\
\hline $\mathrm{G}_{12 \mathrm{~s}}(\mathrm{psi})$ & 305593 & $\varepsilon_{1 \mathrm{C} \text {,alw }}(\mathrm{in} / \mathrm{in})$ & -0.00547 & $\mathrm{X}_{\mathrm{C}}(\mathrm{psi})$ & -104841 \\
\hline $\mathrm{Nu}_{12}$ & 0.3 & $\varepsilon_{2 \mathrm{C}, \text { alw }}(\mathrm{in} / \mathrm{in})$ & -0.01108 & $\mathrm{Y}_{\mathrm{C}}(\mathrm{psi})$ & -12845 \\
\hline
\end{tabular}

( ) : quasi-iso laminate tests result

Figure 12-14 shows the margin of safety calculated on upper/lower skin. As same as in aforementioned figures, the highlighted in read is the area of showing the margin of minus.

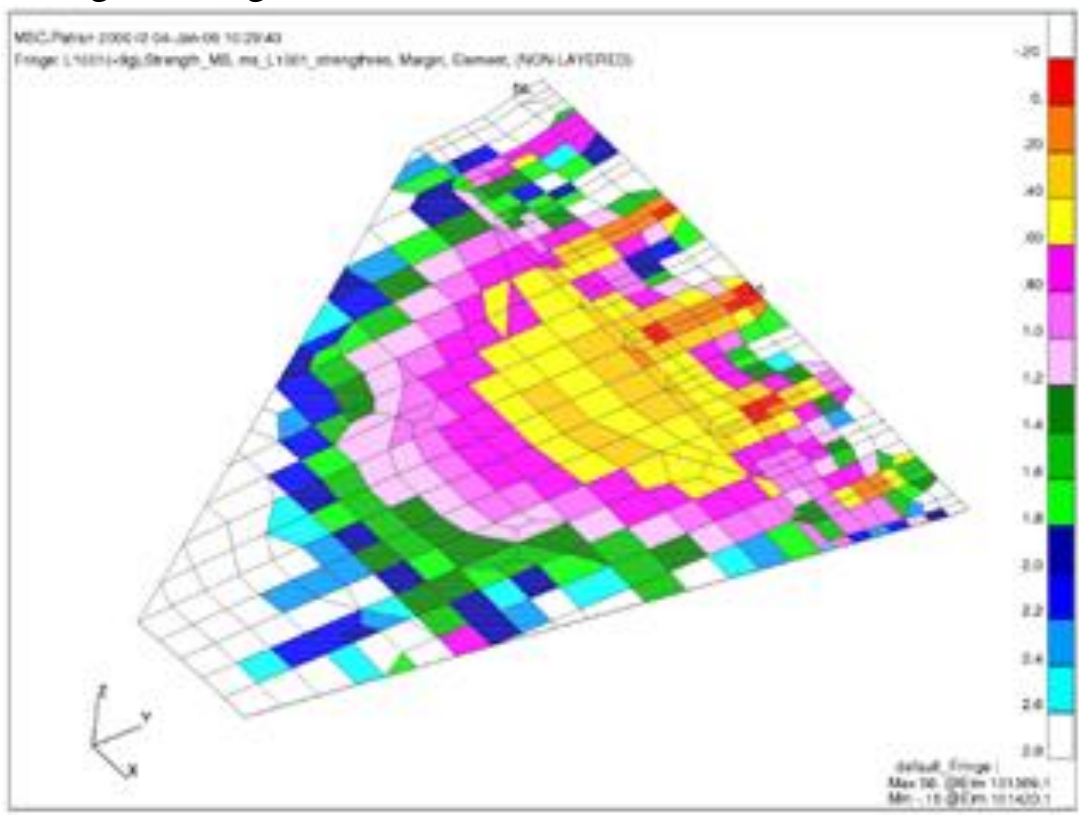


Figure 12. Open Hole Strength M.S. - Upper Skin (+9g).

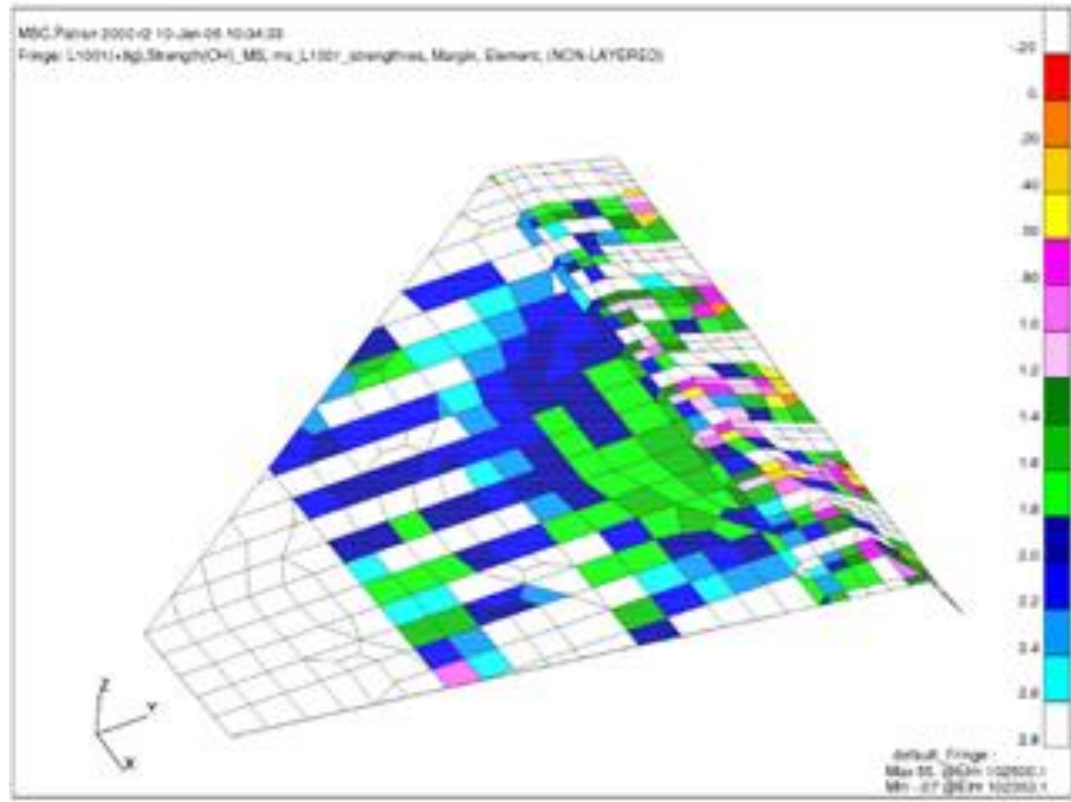

Figure 13. Open Hole Strength M.S. - Lower Skin (+9g).

As for the upper and lower skin which are linked to the wing attach fitting show the minus margin as in open hole strength perspective. This part is actually the one where a lot of loads have to be transferred, the local reinforcement is required.

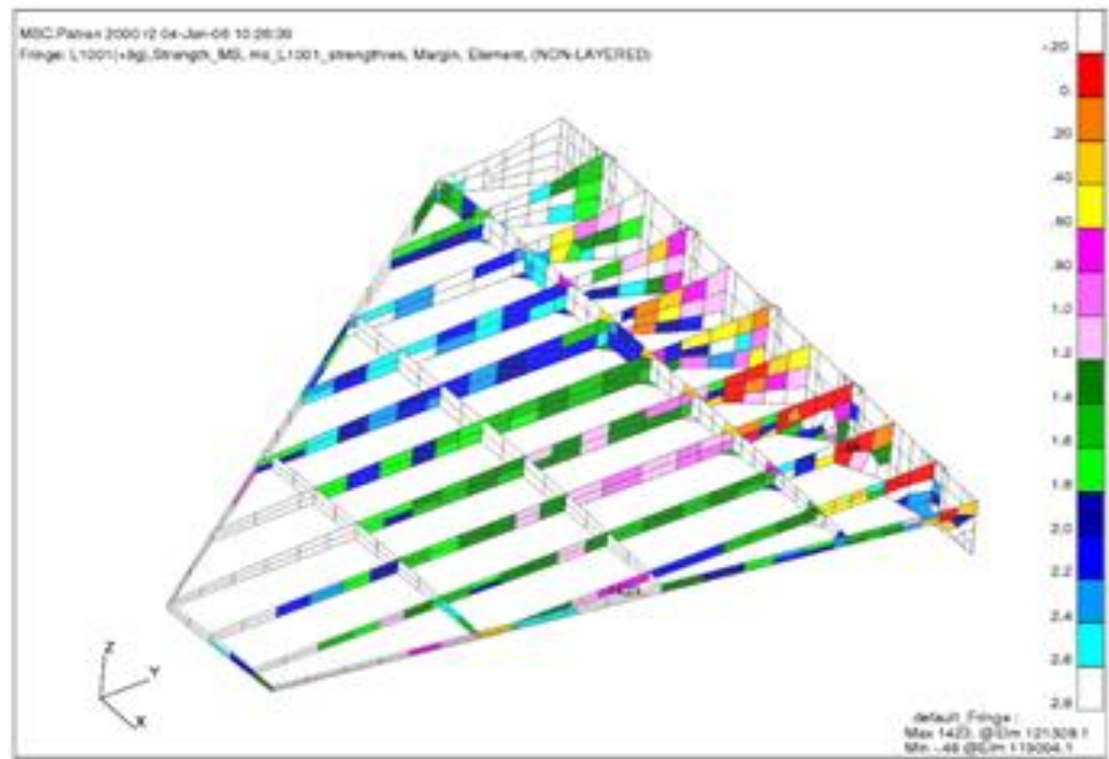


Figure 14. Open Hole Strength M.S. - Spars (+9g)

\section{Verification of Aircraft Wing FE Model}

The structures of aircraft are manufactured by each design requirements and its conformity is verified by tests. In this paragraph, the whiff tree was constructed on the main wing specimen, by applying the 100\% design load and $150 \%$ design load, the damage would not be created during tests and verified analysis results. The specimen was installed by connecting the shackle and tube to the fixture, this part is the one where the actual wings are assembled to the aircraft fuselage. Once installed, the grip was fixed on the aircraft wings and connected the whiff tree. The grip was intended for transferring load to the skin and slat when adding load, the rubber pad was installed at the inside of grip so that it can contact to the specimen.

In addition, the load was compensated so that the load could not be transferred to the specimen due to the weight and dead load. The detailed configuration of test fixture can be found in Figure 15. This experiment is an example to verify the full-scaled finite element model and its analysis result was compared with the amount of deflection measured in the structural test on several static loads conducted previously.

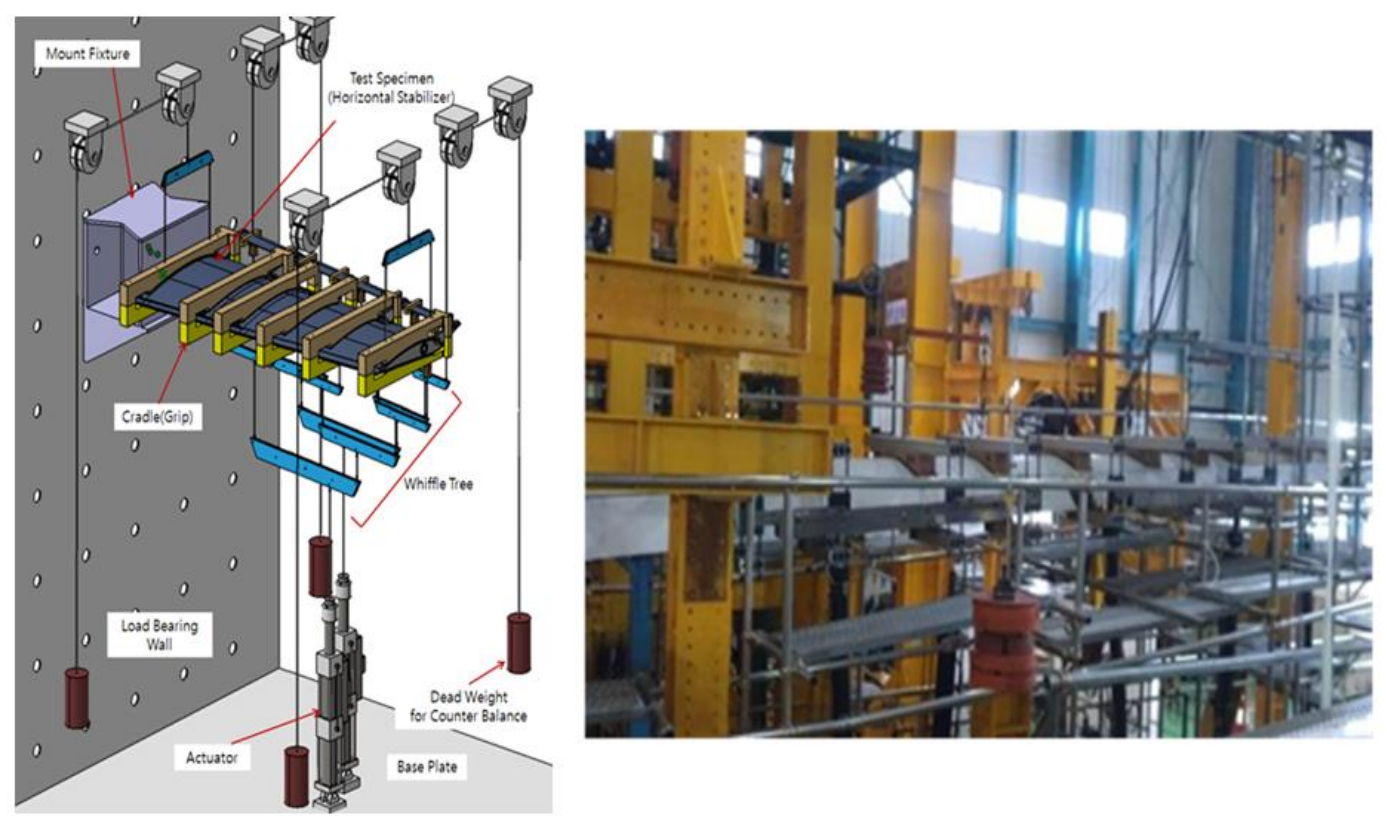


International Journal of Aviation, Aeronautics, and Aerospace, Vol. 6 [2019], Iss. 2, Art. 1

Figure 15. Configuration of whiffle tree and wing specimen. 
The compared result on amount of deflection was shown in Figure 16 and as for the strain gage, three types of strain gages, Rosette, Vesette, and Axial, were fixed on the measuring part and test required part and extracted test result. As a result of test, it can be confirmed that the errors of FEM and Test were created within $\pm 4 \%$.

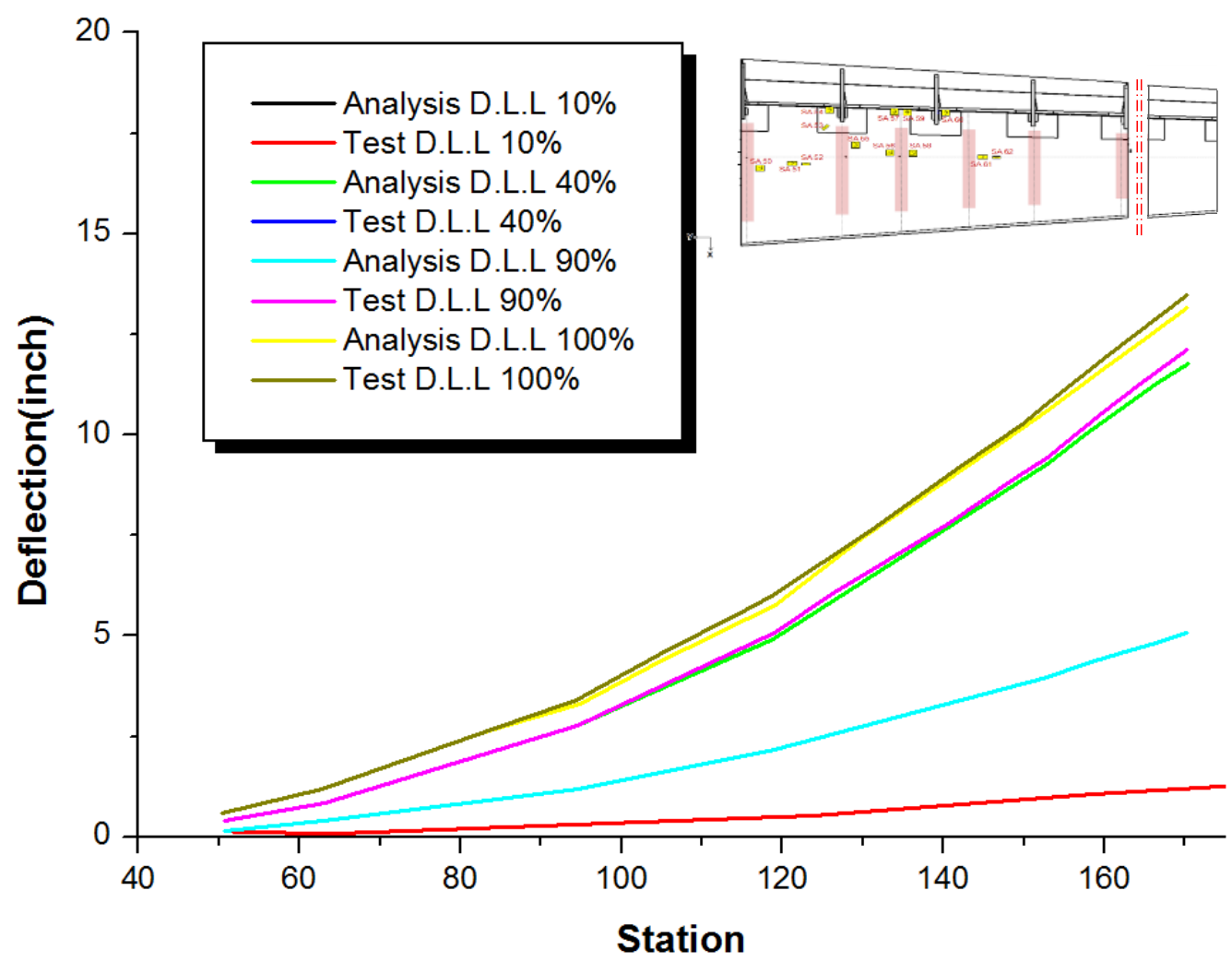

Figure16. Comparison of test results with prediction of wing deflection.

\section{Conclusions}

In this paper, the internal force calculation based on the finite element method, load path evaluation and initial sizing method were presented in order to conduct the structural analysis of multi-spar type of military aircraft at the basic design phase.

In the finite element model, the one-dimensional rod element without bending stiffness, two-dimensional membrane and shear panel elements were basically facilitated. As for the initial sizing, the margin of safety of each structure 
set to be more than 0 within the margin of error based on allowable load to all load cases and the initial sizing system was established by iterated calculation of structural analysis solver.

In addition, the internal loads of each structure including the load of wings and fuselage, flaperon and hinge load and moment of leading-edge flap from the stress level of each finite element were calculated.

Also, it was verified that no permanent deformation on the specimen which is the test requirement on design load by verification test of main wing structure. Prior to reaching to the ultimate load, it was proved that there was any fracture on the specimen so that the design was validated.

The finite element modeling and initial sizing methods presented in this paper are part of researches on development of computational structural analysis methods and standardization and expected to be facilitated as a basic data for structural analysis of various aircraft in the future. 


\section{References}

Bergan, A., Bakuckas, J., Awerbuch, J., \& Tan, T.-M. (2014). Assessment of damage containment features of a full-scale PRSEUS fuselage panel. Composite Structures, 113, 174-185.

Bhattacharya, P., Suhail, H., \& Sinha, P. K. (2002). Finite element analysis and distributed control of laminated composite shells using LQR/IMSC approach. Aerospace Science and Technology, 6, 273-281.

Bruhn, E. F. (1973). Analysis and design of flight vehicle structures. Carmel, IN: Jacobs.

Buehrle, R. D., Fleming, G. A., Pappa, R. S., \& Grosveld, F.W. (2000). Finite element model development and validation for aircraft fuselage structures. Paper presetned at the 18th International Modal Analysis Conference, NASA Langley Research Center, San Antonio, TX.

Gennaretti, M., Molica Colella, M., Bernardini, G., Monteggia, C., Fosco, E., \& Ferro, P. (2013). Analysis of vibrations of an innovative civil tiltrotor. Aerospace Science and Technology, 29, 125-134.

Guo, H., Bastien, C., Blundell, M., \& Wood, G. (2014). Development of a detailed aircraft tyre finite element model for safety assessment. Materials \& Design, 53, 902-909.

Herrada, F. J., García-Martínez, J., Fraile, A., Hermanns, L .K. H., \& Montáns, F. J. (2017). A method for performing efficient parametric dynamic analyses 
in large finite element models undergoing structural modifications.

Engineering Structures, 131, 625-638.

Kapidžić, Z., Nilsson, L., \& Ansell, H. (2014). Finite element modeling of mechanically fastened composite-aluminum joints in aircraft structures. Composite Structures, 109, 198-210.

Karaağaçlı, T., Yıldız, E. N., \& Nevzat Özgüven, H. (2012). A new method to determine dynamically equivalent finite element models of aircraft structures from modal test data. Mechanical Systems and Signal Processing, 31, 94-108.

Kongo Kondé, A., Rosu, I., Lebon, F., Brardo, O., \& Devésa, B. (2013). On the modeling of aircraft tire. Aerospace Science and Technology, 27, 67-75.

Kumar, S., \& Mishra, P. C. (2016). Finite element modeling for structural strength of quadcoptor type multi mode vehicle. Aerospace Science and Technology, 53, 252-266.

Lim, J. H. (2014). A correlation study of satellite finite element model for coupled load analysis using transmissibility with modified correlation measures. Aerospace Science and Technology, 33, 82-91.

Niu, M. C. Y. (1988). Airframe structural design. San Fransisco, CA: Technical. Sasaki, S., Kono, A., \& Takahashi, S. (2014). Improvement in prediction accuracy by finite element methods of stretch-formed aluminum alloy sheets with a large aspect ratio. Procedia Engineering, 81, 927-932. 
Swift, T. (1990). Repairs to damage tolerant aircraft. Paper presented at the International Symposium on Structural Integrity of Aging Airplanes, Atlanta, GA.

Tang, J., Xi, P., Zhang, B., \& Hu, B. (2013). A finite element parametric modeling technique of aircraft wing structures. Chinese Journal of Aeronautics, 26, 1202-1210.

Truong, K.-V., Yeo, H., \& Ormiston, R.A. (2013). Structural dynamics modeling of rectangular rotor blades. Aerospace Science and Technology, 30, 293-305.

van der Ven, H., Bakker, R. J. J., van Tongeren, J. H., Bos, M. J., \& Münninghoff, N. (2012). A modelling framework for the calculation of structural loads for fatigue life prediction of helicopter airframe components. Aerospace Science and Technology, 23, 26-33.

Wittenberg, T. C., van Baten, T. J., \& de Boer, A. (2001). Design of fiber metal laminate shear panels for ultra-high capacity aircraft. Aircraft Design, 4, 99-113.

Yan, Y., Wang, H.-b., \& Wan, M. (2012). FEM modelling for press bend forming of doubly curved integrally stiffened aircraft panel. Transactions of Nonferrous Metals Society of China, 22, 39-47. 
Author Information:

\author{
Jun Hwan Jang ${ }^{\mathrm{a}}$, Sang Ho Ahn ${ }^{\mathrm{b} *}$ \\ ${ }^{a}$ Department of Mechanical design Engineering, Yuhan Univesity, Bucheon-si, \\ Gyeonggi-do, Korea \\ b* Department of Automobile Engineering, Shinhan University, Korea
}

*Corresponding author. Email: drshahn@ naver.com 